
ISSN 0103-9954

\title{
EFEITO DO INTERVALO DE TEMPO ENTRE COLETA/PREPARO E ESTAQUEAMENTO NO ENRAIZAMENTO DE MINIESTACAS DE CLONES DE Eucalyptus urophylla $\mathrm{x}$ Eucalyptus grandis
}

\author{
EFFECT OF THE TIME INTERVAL BETWEEN COLLECTION/PREPARATION \\ AND PLANTATION ON THE ROOTING OF MINICUTTINGS \\ OF Eucalyptus urophylla $\mathrm{x}$ Eucalyptus grandis CLONES
}

Lucas Amaral de Melo ${ }^{1}$ Aloisio Xavier ${ }^{2}$ Haroldo Nogueira de Paiva ${ }^{3}$

Antônio Marcos Rosado ${ }^{4}$ Silvano Rodrigues Borges ${ }^{5}$ Antonio Claudio Davide ${ }^{6}$

\begin{abstract}
RESUMO
O objetivo deste trabalho foi avaliar o efeito do intervalo de tempo entre coleta/preparo e estaqueamento no enraizamento de miniestacas em quatro clones de Eucalyptus urophylla $\mathrm{x}$ Eucalyptus grandis. O delineamento experimental utilizado foi o inteiramente casualizado, arranjo bifatorial com parcelas subdivididas, tendo os intervalos de tempo nas parcelas ( 0,2 e 4 horas) e clones nas subparcelas $\left(\mathrm{C}_{1}, \mathrm{C}_{2}, \mathrm{C}_{3}\right.$ e $\left.\mathrm{C}_{4}\right)$, em três repetições de 192 plantas cada. Avaliou-se o enraizamento e a sobrevivência de miniestacas na saída da casa de vegetação e casa de sombra, a sobrevivência, o crescimento e a qualidade do sistema radicular de mudas aos 50 dias de idade. Em três dos quatro clones estudados, períodos de armazenamento das miniestacas superiores a 2 horas causam redução significativa no percentual de enraizamento e na sobrevivência das mudas aos 50 dias de idade. No entanto, o clone $\mathrm{C}_{2}$ apresenta a máxima eficiência técnica para enraizamento na saída da casa de sombra e para sobrevivência das mudas aos 50 dias, quando suas miniestacas são armazenadas por, respectivamente, 2,3 e 2,5 horas; assim como apresenta maior crescimento em altura, quando armazenadas por 4 horas. Em todos os clones, mudas provenientes de miniestacas armazenadas por 4 horas apresentam qualidade do sistema radicular inferior ao sistema radicular de mudas obtidas a partir de miniestacas com 0 e 2 horas de armazenamento.
\end{abstract}

Palavras-chave: miniestaquia; clonagem; silvicultura clonal.

\begin{abstract}
This study aimed to assess the effects of the time interval between the collection/preparation and plantation on the rooting of minicuttings of four Eucalyptus urophylla $\mathrm{x}$ Eucalyptus grandis clones. The experimental design used was entirely randomized, bi-factorial and arranged with sub-divided plots, being time intervals in plots $\left(0,2\right.$ and 4 hours) and the clones in subplots $\left(\mathrm{C}_{1}, \mathrm{C}_{2}, \mathrm{C}_{3}\right.$ and $\left.\mathrm{C}_{4}\right)$, with three replications of 192 plants each. The rooting and the survival of minicuttings in the greenhouse exit and in the shade house, the survival, the growth and the root system quality of 50-day-old seedlings were assessed. Among the
\end{abstract}

1. Engenheiro Florestal, Doutorando do Programa de Pós-graduação em Engenharia Florestal, Departamento de Ciências Florestais, Universidade Federal de Lavras, Caixa Postal 3037, CEP 37200-000, Lavras (MG). Bolsista da FAPEMIG. lucas.amaral@ufv.br

2. Engenheiro Florestal, Dr., Professor Associado do Departamento de Engenharia Florestal, Universidade Federal de Viçosa, Av. PH Rolfs s/n, CEP 36571-000, Viçosa (MG). xavier@ufv.br

3. Engenheiro Florestal, Dr., Professor Associado do Departamento de Engenharia Florestal, Universidade Federal de Viçosa, Av. PH Rolfs s/n, CEP 36571-000, Viçosa (MG). hnpaiva@ufv.br

4. Engenheiro Florestal, Dr., Melhorista Florestal, CENIBRA- Celulose Nipo Brasileira S.A., Rodovia de Ligação, BR 381 a Belo Oriente, CEP 35195-000, Belo Oriente (MG). antonio.rosado@cenibra.com.br

5. Engenheiro Florestal, Doutorando do Programa de Pós-graduação em Solos e Nutrição de Plantas, Departamento de Solos, Universidade Federal de Viçosa, Av. PH Rolfs s/n, CEP 36571-000, Viçosa (MG). borges@yahoo.com.br

6. Engenheiro Agrônomo, Dr., Professor Titular do Departamento de Ciências Florestais, Departamento de Ciências Florestais, Universidade Federal de Lavras, Campus UFLA, Caixa Postal 3037, CEP 37200-000, Lavras (MG). acdavide@dcf.ufla.br

Recebido para publicação em 28/08/2009 e aceito em 26/10/2010 
four clones studied, it was observed, in three ones, that storage periods of the minicuttings above two hours caused significant reduction in the percentage of rooting and in the survival of 50-day-old seedlings. However, the clone $\mathrm{C}_{2}$ presents the most efficient technique for rooting in the shade house exit and the survival of 50-day-old seedlings when their minicuttings are stored for 2.3 and 2.5 hours, respectively; as much as it presents greater height growth, when the minicuttings were stored during 4 hours. In all clones, those seedlings from minicuttings stored during 4 hours present lower quality of root system than plants obtained from cuttings with 0 and 2 hours of storage.

Keywords: mini-cutting; cloning; clonal sylviculture (forestry).

\section{INTRODUÇÃO}

Atualmente, a miniestaquia é a técnica de propagação vegetativa mais utilizada pelas empresas do setor florestal brasileiro visando à produção de mudas clonais de Eucalyptus. Avanços destacados têm ocorrido no processo, buscando o aperfeiçoamento e a adequação da tecnologia para novos clones. No entanto, ainda persistem algumas dificuldades no entendimento de alguns fatores envolvidos no enraizamento das miniestacas de algumas espécies e clones.

Dentre os fatores envolvidos no enraizamento de miniestacas, destacam-se a ocorrência de injúrias, o balanço hormonal, a constituição genética da planta matriz, o nível endógeno de inibidores, as condições nutricionais e hídricas da planta doadora de propágulos (ALFENAS et al., 2004), o tempo despendido desde a coleta até o estaqueamento (GOULART e XAVIER, 2008), as reações de oxidação (WENDLING, 2002), a maturação/juvenilidade dos propágulos, a luminosidade, a temperatura e a umidade relativa do ar (PAIVA e GOMES, 2005; XAVIER et al., 2009).

Quanto ao armazenamento do material vegetativo, o tempo transcorrido entre a coleta/ preparo e o estaqueamento da miniestaca no substrato para enraizamento merece atenção especial. Ferrari et al. (2004), por exemplo, recomendaram intervalos inferiores a 15 minutos; no entanto, em algumas situações de grandes distâncias de coleta das brotações e grande número de mudas a serem produzidas, há a necessidade de armazenamento das estacas por períodos maiores (ALFENAS et al., 2004).

Segundo Goulart e Xavier (2008) e Xavier et al. (2009), o tempo de armazenamento das miniestacas e o sucesso do enraizamento destas dependem da umidade relativa, temperatura, espécie, patógenos, condições de crescimento da planta doadora de propágulos e da época de coleta das brotações destinadas ao processo de estaquia. A época do ano em que o material é coletado pode exercer grande influência no enraizamento das estacas, já que as condições fisiológicas da planta doadora podem ser influenciadas pelas variações sazonais (PAIVA e GOMES, 2005).

Dentrealgumas práticasquevisampossibilitar maior tempo de armazenamento das miniestacas, de forma geral, destacam-se a redução da temperatura e da luz, o aumento da umidade relativa do ar e a aplicação de antitranspirantes. Essas condições buscam manter o vigor, a turgescência e minimizar as atividades metabólicas das brotações, visando garantir o máximo potencial de enraizamento da estaca (XAVIER et al., 2009).

Goulart e Xavier (2008) salientaram que, durante o armazenamento, deve-se buscar a minimização do estresse hídrico, a prevenção de doenças fúngicas e a manutenção das reservas de carboidratos e de outras substâncias importantes no processo de enraizamento adventício. Os mesmos autores, estudando o efeito do tempo de armazenamento (em dias) no enraizamento de miniestacas de quatro clones de Eucalyptus grandis x Eucalyptus urophylla, observaram que, em todos os genótipos, ocorreu decréscimo nos índices de enraizamento na saída da casa de sombra conforme aumentou o tempo de armazenamento das miniestacas.

Quanto à manutenção das condições ambientais e status fisiológico da planta doadora de propágulos, as estacas devem ser coletadas no seu máximo vigor vegetativo e de turgidez, em razão da vulnerabilidade das estacas recém-preparadas para suportar o estresse hídrico, diante da dificuldade de reidratação dos tecidos sem a presença de um sistema radicular (XAVIER et al., 2009).

A importância de se conhecer os fatores que afetam a formação de raízes e suas implicações está diretamente relacionada ao sucesso ou fracasso na produção de mudas por estaquia. Da mesma maneira, essas informações podem subsidiar o planejamento

Ci. F1., v. 21, n. 4, out.-dez., 2011 
logístico do processo de produção em viveiros clonais. Dessa forma, o objetivo deste trabalho foi avaliar o efeito do intervalo de tempo entre a coleta/preparo e estaqueamento de miniestacas no enraizamento de quatro clones de Eucalyptus urophylla x Eucalyptus grandis.

\section{MATERIAL E MÉTODO}

\section{Material experimental}

O presente trabalho foi realizado no período de setembro a novembro de 2008, no Viveiro Florestal da empresa Celulose Nipo-Brasileira S. A. CENIBRA, localizada no município de Belo Oriente, Minas Gerais. O município de Belo Oriente localizase na região do Vale do Rio Doce, com clima do tipo Cwa (subtropical, chuvoso e mesotérmico), segundo a classificação de Köeppen, latitude de $19^{\circ} 18^{\prime} 23$ "S, longitude $42^{\circ} 22^{\prime} 46^{\prime}$ 'W e altitude de $363 \mathrm{~m}$. Apresenta precipitação média anual de $1.233 \mathrm{~mm}$, temperatura média anual de $21^{\circ} \mathrm{C}$, com máxima de $27^{\circ} \mathrm{C}$ e mínima de $14^{\circ} \mathrm{C}$.

Foram utilizadas miniestacas de quatro clones de Eucalyptus urophylla $\mathrm{x}$ Eucalyptus grandis

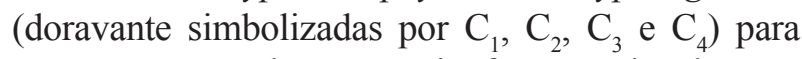
o presente estudo, as quais foram coletadas em minicepas estabelecidas em minijardim clonal, com manejo e nutrição de acordo com os procedimentos adotados pela empresa CENIBRA. O critério de seleção desses clones foi baseado, principalmente, nos percentuais médios de enraizamento, levantados pela empresa ao longo do processo produtivo, e disponibilidade de material vegetativo para o processo de produção de mudas clonais. Foi selecionado um clone com percentual médio de enraizamento acima de $90 \%\left(C_{1}\right)$, dois entre 80 e $90 \%\left(C_{2}\right.$ e $\left.C_{4}\right)$ e um quarto, inferior a $80 \%\left(\mathrm{C}_{3}\right)$.

\section{Manejo do minijardim clonal}

Conforme a técnica de miniestaquia, descrita por Xavier e Wendling (1998), Higashi et al. (2000), Wendling et al. (2000a), Alfenas et al. (2004), Assis et al. (2004) e Xavier et al. (2009) e, de acordo com os procedimentos de manejo adotados pela CENIBRA, o minijardim clonal foi constituído de minicepas, obtidas pelo enraizamento de miniestacas, implantado em canaletas de alvenaria, preenchidas com brita no fundo e areia lavada no restante do espaço.

A irrigação e a nutrição mineral foram efetuadas através de sistema automatizado de fertirrigação por gotejamento, conforme procedimentos operacionais adotados pela CENIBRA
(Tabela 1). A cada três horas, o sistema era acionado, irrigando por um período de 6 minutos. $\mathrm{O}$ excesso da solução nutritiva drenava pelo fundo da canaleta e retornava, por meio de tubulações, à caixa de armazenamento da solução, sendo esta monitorada regularmente e trocada a cada sete dias; diariamente, eram mensurados a condutividade elétrica (Ec mantida entre 1,0 e $1,5 \mathrm{mS} \mathrm{cm}^{-1}$ ) e o $\mathrm{pH}$ da solução (mantido entre 5,5 e 6,5).

\section{Obtenção, preparo, estaqueamento e enraizamento das miniestacas}

As miniestacas foram coletadas em minicepas estabelecidas no minijardim clonal, preparadas com dimensões de 6 a $8 \mathrm{~cm}$ de comprimento e mantendose dois pares de folhas reduzidas à metade de sua dimensão original. Para manter as condições de turgescência do material vegetativo, as miniestacas foram acondicionadas em caixas de isopor, efetuandose pulverizações com água por meio de pulverizador manual, em intervalos de tempo inferiores a 5 minutos até a submissão aos tratamentos. O período compreendido entre a coleta das miniestacas e seu preparo foi sempre inferior a 20 minutos.

Após a coleta e o preparo das miniestacas, estas receberam os seguintes tratamentos: $\mathrm{T} 1{ }_{-}$ estaqueamento imediatamente após o preparo (0 hora); T2 e T3, referentes ao estaqueamento das miniestacas após o armazenamento em casa de vegetação climatizada por 2 e 4 horas, respectivamente. Miniestacas dos tratamentos T2 e T3 foram mantidas armazenadas em caixas de isopor providas de orifícios no fundo e sem tampa,

TABELA 1: Solução nutritiva estoque usada no minijardim clonal.

TABLE 1: Stock nutrient solution used in clonal mini-garden.

\begin{tabular}{lc}
\hline Fertilizante & Dose $\left(\mathrm{g} 1000 \mathrm{~L}^{-1}\right)$ \\
\hline Nitrato de cálcio & $80.000,0$ \\
Sulfato de amônio & $27.800,0$ \\
Ácido fosfórico & $5.000,0$ \\
Cloreto de potássio & $20.000,0$ \\
Sulfato de magnésio & $14.400,0$ \\
Ácido bórico & 311,1 \\
Sulfato de zinco & 27,8 \\
Sulfato de cobre & 42,2 \\
Sulfato ferroso & $1.222,2$ \\
EDTA dissódico & $1.833,3$ \\
Sulfato de manganês & 666,7 \\
Molibdato de sódio & 11,1 \\
\hline
\end{tabular}


no interior da casa de vegetação climatizada, em condições de temperatura em torno de $27^{\circ} \mathrm{C}$ e umidade relativa do ar acima de $80 \%$.

As miniestacas foram estaqueadas em substrato composto por uma mistura de casca de arroz carbonizada e vermiculita de granulometria média (1:1), enriquecida com $8 \mathrm{~kg} \mathrm{~m}^{-3}$ de superfosfato simples, $694 \mathrm{~g} \mathrm{~m}^{-3}$ de sulfato de amônio, $208 \mathrm{~g} \mathrm{~m}^{-3}$ de cloreto de potássio, 13,9 $\mathrm{g} \mathrm{m}^{-3}$ de sulfato de zinco, $13,9 \mathrm{~g} \mathrm{~m}^{-3}$ de sulfato de cobre, $13,9 \mathrm{~g} \mathrm{~m}^{-3}$ de sulfato de manganês e $27,8 \mathrm{~g} \mathrm{~m}^{-3}$ de ácido bórico. Foram utilizados como recipientes tubetes cônicos com $12 \mathrm{~cm}$ de comprimento e $55 \mathrm{~cm}^{3}$ de capacidade, previamente esterilizados em água quente a $80^{\circ} \mathrm{C}$ durante 30 segundos, conforme método descrito por Alfenas et al. (2004).

Oenraizamentodasminiestacasfoiconduzido em casa de vegetação climatizada do viveiro florestal da CENIBRA, visando à obtenção das condições de temperatura em torno de $27^{\circ} \mathrm{C}$ e de umidade relativa do ar acima de $80 \%$, com permanência de 18 dias. Posteriormente, as miniestacas foram transferidas para a área de sombreamento (permanência de 10 dias para aclimatização) e, finalmente, para a área de crescimento a pleno sol até completarem 50 dias de idade.

O delineamento experimental utilizado foi o inteiramente casualizado, arranjo bifatorial com parcelas subdivididas, sendo as parcelas compostas pelos intervalos de tempo $(0,2$ e 4 horas $)$ e as subparcelas, pelos clones $\left(\mathrm{C}_{1}, \mathrm{C}_{2}, \mathrm{C}_{3}\right.$ e $\left.\mathrm{C}_{4}\right)$, em três repetições compostas por 192 plantas cada.

\section{Avaliações experimentais}

Foram avaliados os percentuais de sobrevivência das miniestacas e de miniestacas com raízes maiores que $10 \mathrm{~cm}$ (miniestacas com raízes saindo pela base do tubete) na saída da casa de vegetação (aos 18 dias após o estaqueamento), de sobrevivência das miniestacas e de miniestacas com raízes maiores que $10 \mathrm{~cm}$ na saída da casa de sombra (aos 28 dias após o estaqueamento). E aos 50 dias, avaliaram-se o percentual de sobrevivência, a altura $(\mathrm{cm})$ e o diâmetro de colo $(\mathrm{mm})$ das mudas obtidas.

Para a medição da altura e diâmetro do colo de mudas aos 50 dias, foram analisadas, aleatoriamente, oito plantas por clone/repetição. A altura foi obtida com auxílio de régua graduada em milímetros e o diâmetro de colo, com a utilização de paquímetro digital. Estas mudas foram utilizadas também para avaliação qualitativa do sistema radicular. Nesta análise, foi avaliada a qualidade do conjunto substrato/sistema radicular, observando o grau de agregação do substrato, quando as mudas eram retiradas dos tubetes.

Os dados obtidos foram analisados segundo metodologia proposta por Banzatto e Kronka (2006), na qual a transformação foi feita por meio da fórmula: $\operatorname{arcsen}(x / 100)^{1 / 2}$, sendo $x$, o valor percentual. A partir dos dados encontrados para as características quantitativas avaliadas, foram realizadas as análises de variância e teste de médias ou análises de regressão. A ANOVA e os testes de médias foram feitos com auxílio do Programa Estatístico Sis Var (FERREIRA, 2000). As equações de regressão foram obtidas por meio do programa CurveExpert 1.3 (HYAMS, 1997).

\section{RESULTADOS E DISCUSSÃO}

A análise de variância revelou efeito significativo, pelo teste $\mathrm{F}(\mathrm{P}<0,05)$, da interação "clone x tempo" para as características porcentagem de miniestacas com raízes maiores que $10 \mathrm{~cm}$ na saída da casa de vegetação (PSCV10), e na saída da casa de sombra (PSCS10), porcentagem de sobrevivência (PS50) e altura (ALT) de mudas aos 50 dias de idade (Tabela 2).

Os coeficientes de variação experimental encontrados variaram de 1,1 a $25,2 \%$, evidenciando níveis aceitáveis de precisão experimental em relação às características estudadas, de acordo com os valores encontrados na literatura consultada (WENDLING et al., 2000a; WENDLING et al., 2000b; TITON et al., 2003; GOULART e XAVIER, 2008).

Os clones $\mathrm{C}_{2}$ e $\mathrm{C}_{4}$ apresentaram as maiores porcentagens de sobrevivência de miniestacas na saída da casa de sombra em relação aos clones $\mathrm{C}_{1} \mathrm{e}$ $\mathrm{C}_{3}$ (Figura 1). Este último $\left(\mathrm{C}_{3}\right)$, por sua vez, atingiu a menor porcentagem de sobrevivência quando comparado com os demais. Aos 50 dias, foi possível observar diferenças significativas entre clones em relação à característica diâmetro de colo. Mudas do clone $\mathrm{C}_{1}$ apresentaram diâmetro de colo $(\mathrm{mm})$ maior, quando comparadas com mudas dos demais clones. Todavia, o diâmetro médio de colo de mudas em todos os materiais genéticos estudados está acima do limite mínimo $(2 \mathrm{~mm})$ normalmente exigido pelo critério de qualidade utilizado no setor florestal.

Ao analisar o enraizamento na saída da casa de vegetação (PSCV10) e na saída da casa de sombra (PSCS10), observa-se que três dos quatro clones estudados apresentaram uma tendência de 
TABELA 2: Resultados da análise de variância das características de porcentagem de sobrevivência (PSCV) e de miniestacas com raízes maiores que $10 \mathrm{~cm}$ na saída da casa de vegetação (PSCV10), porcentagem de sobrevivência (PSCS) e de miniestacas com raízes maiores que $10 \mathrm{~cm}$ na saída da casa de sombra (PSCS10), porcentagem de sobrevivência (PS50), altura (ALT) e diâmetro de colo (DC) de mudas aos 50 dias de idade, em função do intervalo de tempo entre coleta/preparo e estaqueamento das miniestacas, dos quatro clones de Eucalyptus urophylla $\mathrm{x}$ Eucalyptus grandis.

TABLE 2: Results of the variance analysis of the characteristics of survival percentage (PSCV) and of minicuttings with roots larger than $10 \mathrm{~cm}$ in the output of the greenhouse (PSCV10), survival percentage (PSCS) and of minicuttings with roots larger than $10 \mathrm{~cm}$ in the shade house exit (PSCS10), survival percentage (PS50), height (ALT) and root collar diameter (DC) of 50-days-old seedlings, in function of the time interval between the collection/preparation and plantation of minicuttings, of the four Eucalyptus urophylla $\mathrm{x}$ Eucalyptus grandis clones.

\begin{tabular}{|c|c|c|c|c|c|c|c|c|}
\hline \multirow{2}{*}{$\begin{array}{l}\text { Fontes de } \\
\text { Variação }\end{array}$} & \multirow[b]{2}{*}{ GL } & \multicolumn{7}{|c|}{ Quadrados Médios } \\
\hline & & $\begin{array}{c}\text { PSCV } \\
(\%)\end{array}$ & $\begin{array}{c}\text { PSCV10 } \\
(\%)\end{array}$ & $\begin{array}{l}\text { PSCS } \\
(\%)\end{array}$ & $\begin{array}{c}\text { PSCS10 } \\
(\%)\end{array}$ & $\begin{array}{l}\text { PS50 } \\
(\%)\end{array}$ & $\begin{array}{l}\text { ALT } \\
(\mathrm{cm})\end{array}$ & $\begin{array}{c}\mathrm{DC} \\
(\mathrm{mm})\end{array}$ \\
\hline Tempo (T) & 2 & $0,0051^{\mathrm{ns}}$ & $0,0268^{\mathrm{ns}}$ & $0,0096^{\mathrm{ns}}$ & $0,0614^{\mathrm{ns}}$ & $0,0419^{\mathrm{ns}}$ & $16,47703^{\mathrm{ns}}$ & $0,04251^{\mathrm{ns}}$ \\
\hline Resíduo 1 & 2 & 0,0051 & 0,0268 & 0,0096 & 0,0614 & 0,0419 & 16,47703 & 0,04251 \\
\hline Clone (C) & 3 & $0,0309^{\text {ns }}$ & $0,4332 *$ & $0,1056^{*}$ & $0,1439 *$ & $0,0715^{*}$ & $41,69328^{*}$ & $0,56833 *$ \\
\hline $\mathrm{T} \times \mathrm{C}$ & 6 & $0,0146^{\mathrm{ns}}$ & $0,0135^{*}$ & $0,0048^{\mathrm{ns}}$ & $0,0119 *$ & $0,0118^{*}$ & $11,06005^{*}$ & $0,02960^{\text {ns }}$ \\
\hline Resíduo 2 & 22 & 0,0122 & 0,0015 & 0,0048 & 0,0002 & 0,0013 & 0,06302 & 0,02320 \\
\hline Média Geral & - & 98,7 & 53,2 & 88,7 & 69,5 & 78,9 & 23,8 & 2,6 \\
\hline CV $1(\%)$ & - & 4,9 & 20,0 & 8,0 & 25,2 & 18,7 & 17,1 & 7,9 \\
\hline CV $2(\%)$ & - & 8,5 & 4,7 & 5,7 & 1,3 & 3,3 & 1,1 & 5,8 \\
\hline
\end{tabular}

Em que: ${ }^{\text {ns }}=$ Não significativo; $*$ = Significativo a $5 \%$ de probabilidade, pelo teste $\mathrm{F}$.
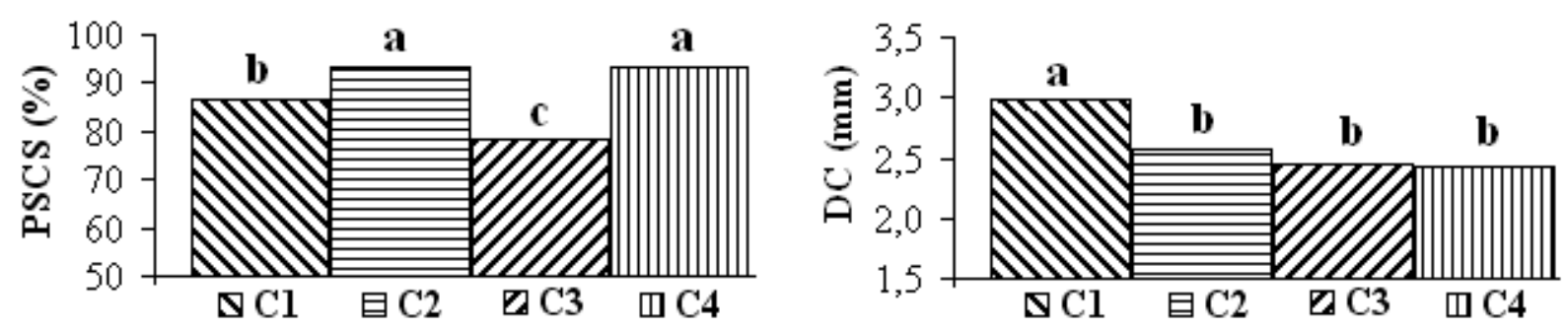

FIGURA 1: Percentual de sobrevivência de miniestacas na saída da casa de sombra (PSCS) e diâmetro de colo de mudas aos 50 dias de idade (DC), em quatro clones de Eucalyptus urophylla $\mathrm{x}$ Eucalyptus grandis. Médias seguidas da mesma letra não diferem entre si, pelo teste de Tukey, a $5 \%$ de probabilidade.

FIGURE 1: Minicuttings survival percentage in the shade house exit (PSCS) and root collar diameter of 50-days-old seedlings (DC) in four Eucalyptus urophylla x Eucalyptus grandis clones. Averages followed by the same letter do not differ from each other, for the test of Tukey, to $5 \%$ of probability. 
decréscimo mais pronunciado do enraizamento após o período de 2 horas de armazenamento (Figura 2). Os clones $\mathrm{C}_{1}$ e $\mathrm{C}_{4}$ apresentaram comportamentos muito parecidos e o clone $\mathrm{C}_{3}$ com percentuais bem abaixo dos demais. No entanto, o clone $\mathrm{C}_{2}$, apresentaria o seu maior percentual de enraizamento na saída da casa de sombra quando armazenado por 2,3 horas. Neste caso, o armazenamento das miniestacas por um período de tempo não muito longo influenciou positivamente no processo de enraizamento do referido clone.

Em determinados casos, como grande quantidade de miniestacas, grandes distâncias entre os locais de coleta e estaqueamento e certos horários de intervalos do expediente, o armazenamento das miniestacas é necessário e, portanto, o conhecimento do comportamento dos materiais a serem propagados torna-se de fundamental importância para evitar perdas e aumentar possíveis ganhos.

De acordo com Floriano (2004), várias substâncias podem induzir ou inibir o enraizamento, sejam elas naturais ou sintéticas. Algumas substâncias alelopáticas estão presentes na matéria orgânica dos substratos e podem ser inibidoras do enraizamento, assim como outros inibidores estão presentes na própria planta que se quer multiplicar. Algumas substâncias podem ser lixiviadas ou diluídas por lavagens sucessivas da estaca ou por banho em água pura (HARTMANN et al., 2002; FLORIANO, 2004). Pode-se deduzir que as

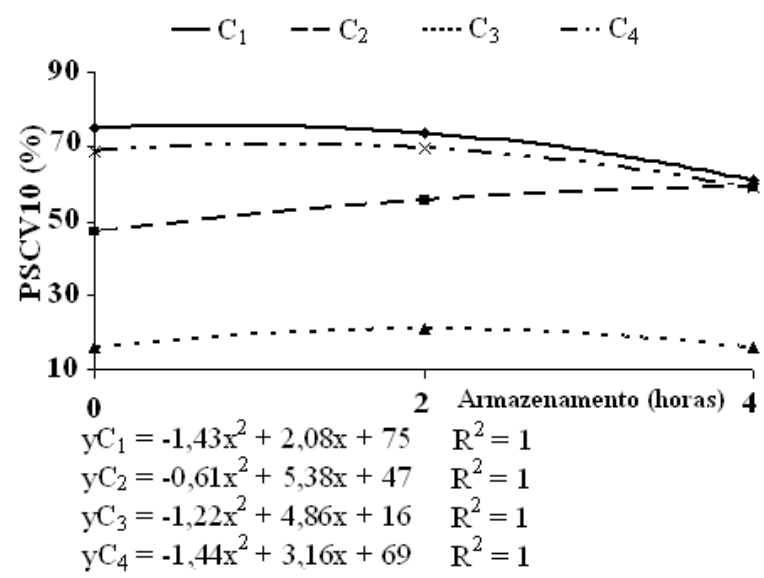

miniestacas do clone $\mathrm{C}_{2}$ possuem alguma substância que afeta negativamente o enraizamento, a qual foi lixiviada com a água pulverizada durante o período de armazenamento.

A sobrevivência das mudas de três clones aos 50 dias de idade foi influenciada negativamente pelo período de armazenamento, mostrando o mesmo comportamento de decréscimo, principalmente a partir de 2 horas. Novamente, o clone $\mathrm{C}_{2}$ apresentou um aumento percentual na sobrevivência das mudas, quando suas miniestacas foram estaqueadas após um período de armazenamento. O referido clone apresentaria a máxima sobrevivência às duas horas e meia (Figura 3).

É possível notar que mudas dos clones $\mathrm{C}_{3}$ e $\mathrm{C}_{4}$ sob armazenamento, apresentaram redução na altura, quando comparadas à altura de mudas sem armazenamento, sendo que mudas do clone $\mathrm{C}_{1}$ apresentariam redução na altura a partir de uma hora e meia de armazenamento. Já para o clone $\mathrm{C}_{2}$, houve aumento na altura das mudas, as quais apresentariam altura máxima quando as miniestacas fossem armazenadas por 4 horas, confirmando o comportamento deste clone observado anteriormente (Figura 3).

Em geral, a recomendação é que o armazenamento de miniestacas para posterior estaqueamento deve ser evitado ao máximo, para a maioria dos casos. No entanto, é possível notar que este fator pode interferir positivamente no processo

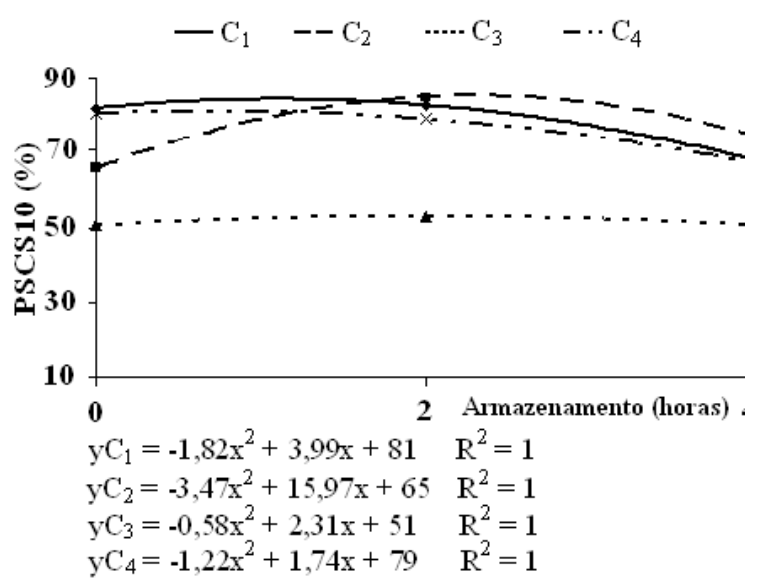

FIGURA 2: Percentual de miniestacas com raízes maiores que 10 centímetros, na saída da casa de vegetação (PSCV10) e na saída da casa de sombra (PSCS10), em função do intervalo de tempo entre coleta/preparo e estaqueamento das miniestacas, dos quatro clones de Eucalyptus urophylla $\mathrm{x}$ Eucalyptus grandis.

FIGURE 2: Percentage of minicuttings with roots larger than $10 \mathrm{~cm}$ in the greenhouse exit (PSCV10) and in the shade house exit (PSCS10), in function of the time interval between collection/ preparation and plantation of minicuttings from the four Eucalyptus urophylla $\mathrm{x}$ Eucalyptus grandis clones. 
de enraizamento para certos materiais genéticos, indicando efeito genotípico.

Pela avaliação qualitativa do sistema radicular de mudas aos 50 dias, foi possível constatar os mesmos resultados obtidos com as características quantitativas (Figura 4). Mudas oriundas de miniestacas submetidas a 4 horas de armazenamento apresentaram maior desagregação do substrato quando comparadas com mudas obtidas de miniestacas estaqueadas após 0 e 2 horas de armazenamento. Dentro de cada intervalo de tempo entre coleta/preparo e estaqueamento, mudas do clone $\mathrm{C}_{1}$ apresentaram melhor agregação do sistema radicular em relação às mudas dos demais clones. No entanto, esta característica foi influenciada, possivelmente, pela maior quantidade de raízes adventícias que este clone possui (dados não apresentados).
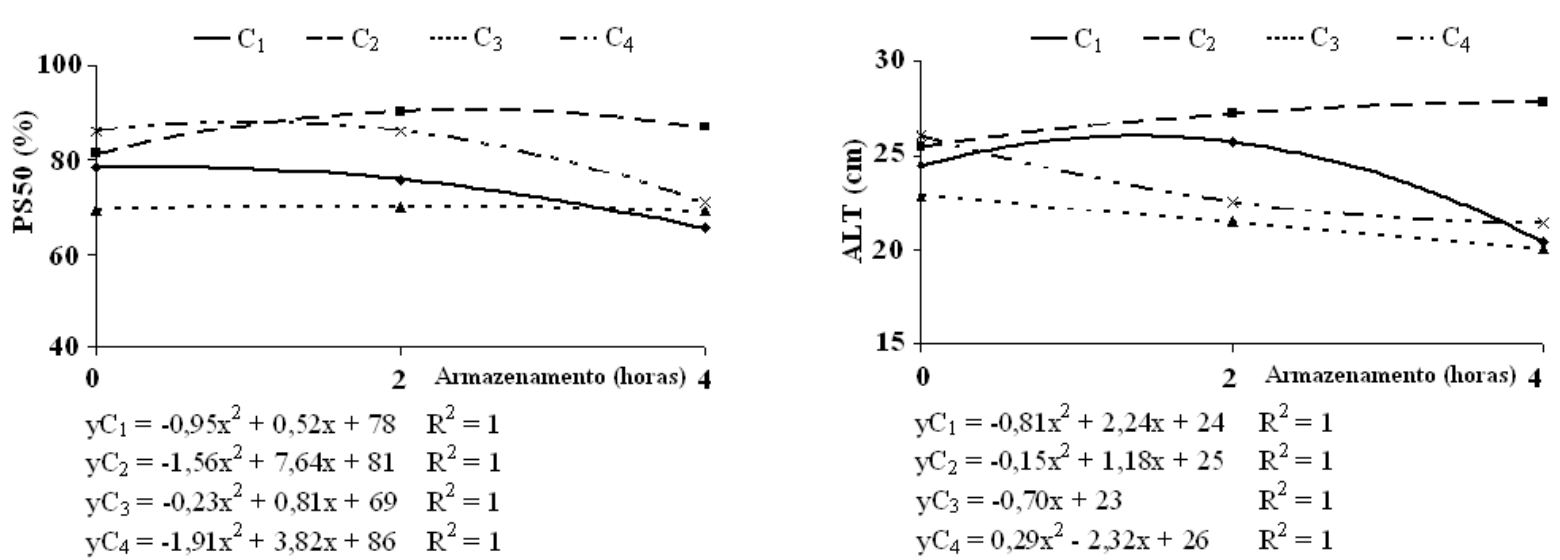

FIGURA 3: Percentual de sobrevivência (PS50) e altura de mudas (ALT) aos 50 dias de idade, em função do intervalo de tempo entre coleta/preparo e estaqueamento das miniestacas, dos quatro clones de Eucalyptus urophylla $\mathrm{x}$ Eucalyptus grandis.

FIGURE 3: Survival percentage (PS50) and height (ALT) of 50-days-old seedlings, in function of the time interval between collection/preparation and plantation of minicuttings from the four Eucalyptus urophylla $\mathrm{x}$ Eucalyptus grandis clones.

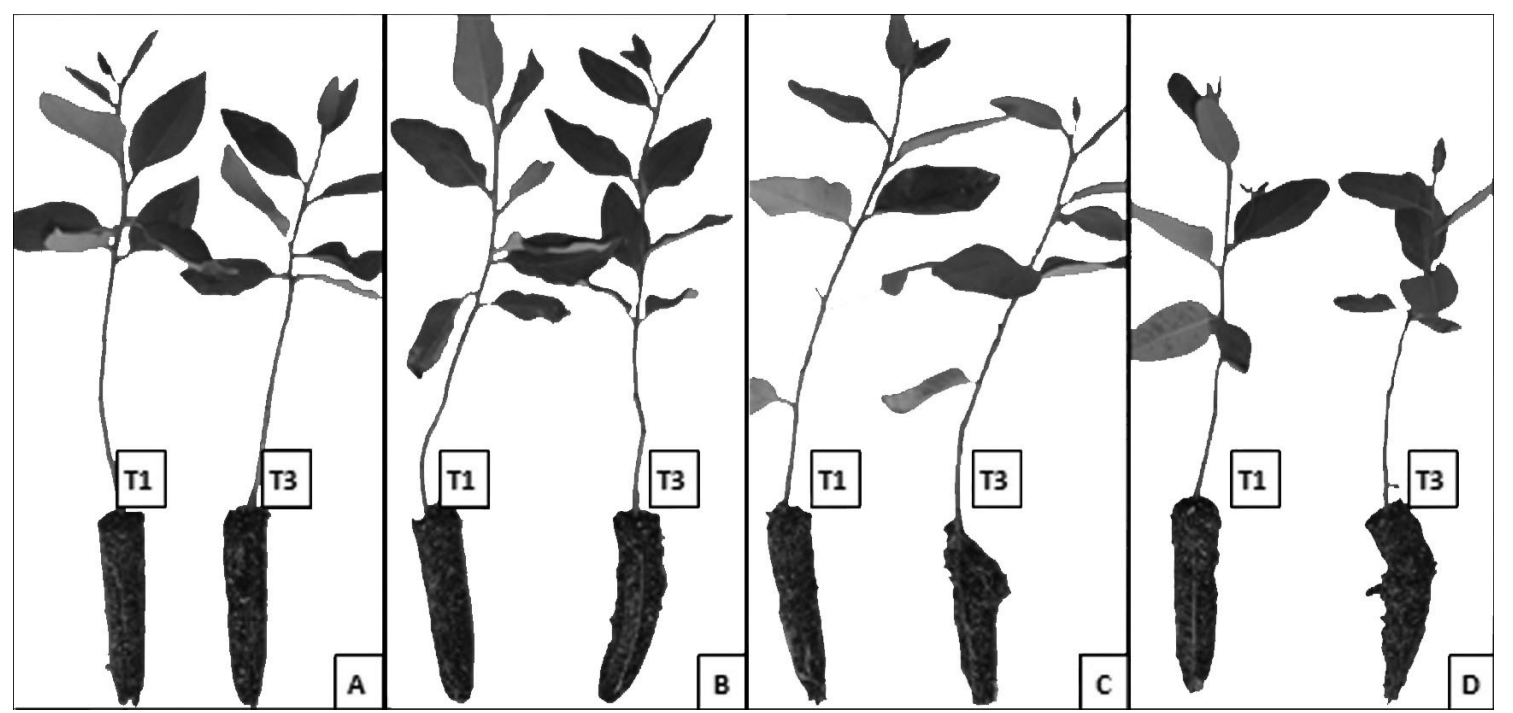

FIGURA 4: Mudas, aos 50 dias de idade, oriundas de miniestacas submetidas ao armazenamento em casa de vegetação. $\mathrm{A}$ : Clone $\mathrm{C}_{1}$; $\mathrm{B}$ : Clone $\mathrm{C}_{2}$; $\mathrm{C}$ : Clone $\mathrm{C}_{3}$; $\mathrm{D}$ : Clone $\mathrm{C}_{4}$; $\mathrm{T} 1$ : Tratamento com 0 hora de armazenamento; T3: Tratamento com 4 horas de armazenamento.

FIGURE 4: 50-days-old seedlings originated from minicuttings submitted to the storage in a greenhouse. A: Clone $\mathrm{C}_{1}$; $\mathrm{B}$ : Clone $\mathrm{C}_{2}$; $\mathrm{C}$ : Clone $\mathrm{C}_{3}$; $\mathrm{D}$ : Clone $\mathrm{C}_{4}$; $\mathrm{T} 1$ : Treatment with 0 hour of storage; $\mathrm{T} 3$ : Treatment with 4 hours of storage. 


\section{CONCLUSÕES}

Os resultados evidenciam que há influência significativa do intervalo de tempo entre coleta/ preparo e estaqueamento de miniestacas no enraizamento dos quatro clones avaliados.

Os quatro clones de Eucalyptus urophylla $\mathrm{x}$ Eucalyptus grandis respondem de forma diferente à imposição do intervalo de tempo entre coleta/ preparo e estaqueamento das miniestacas, indicando efeito genotípico.

De maneira geral, em três dos quatro clones estudados, intervalos de tempo entre coleta/preparo e estaqueamento de miniestacas superiores a 2 horas causam redução significativa no percentual de enraizamento e no crescimento posterior das mudas. No entanto, o armazenamento das miniestacas por um período de tempo não muito longo pode influenciar positivamente o processo de enraizamento de determinados clones.

\section{AGRADECIMENTOS}

À Empresa Celulose Nipo-Brasileira (CENIBRA), pela disponibilização do material experimental (clones) e pelo apoio orçamentário e estrutural na condução da pesquisa e, ao $\mathrm{CNPq}$ (Conselho Nacional de Pesquisa e Desenvolvimento Científico e Tecnológico), pelo suporte financeiro.

\section{REFERÊNCIAS BIBLIOGRÁFICAS}

ALFENAS, A. C. et al. Clonagem e doenças do eucalipto. Viçosa: UFV, 2004. 422 p.

ASSIS, T. F.; FETT NETO, A. G.; ALFENAS, A. C. Current techiniques and prospects for the clonal propagation of hardwoods with emphasis on Eucalyptus. In: Walters, C.; Carson, M. (Eds.) Plantation forest biotechnology for the $21^{\text {st }}$ century, India: Research Signpost, 2004. p. 303333.

BANZATO, D. A.; KRONKA, S. N. Experimentação agrícola. 4. ed. Jaboticabal: FUNEP, 2006. 237 p.

FERRARI, M. P.; GROSSI. F.; WENDLING, I. Propagação vegetativa de espécies florestais. Colombo: Embrapa Florestas, 2004. 22 p. (Embrapa Florestas. Documentos, 94).

FERREIRA, D. F. Análises estatísticas por meio do SisVar para Windows versão 4.0. In: REUNIÃO ANUAL DA REGIÃO BRASILEIRA DA SOCIEDADE INTERNACIONAL DE BIOMETRIA, 45., 2000, São Carlos. Anais... São Carlos: UFSCAR, 2000. p.255-258.

FLORIANO, E. P. Produção de mudas florestais por via assexuada. Santa Rosa: ANORGS, 2004. 37 p. (Caderno Didático, 3)

GOULART, P. B.; XAVIER, A. Efeito do tempo de armazenamento de miniestacas no enraizamento de clones de Eucalyptus grandis x Eucalyptus urophylla. Revista Árvore, Viçosa, v. 32, n. 4, p. 671-677, jul./ago. 2008.

HARTMANN, H. T. et al. Plant propagation: principles and practices. 7th ed. New Jersey: Prentice-Hall, 2002, 880 p.

HIGASHI, E. N.; SILVEIRA, R. L. A.; GONÇALVES, A. N. Propagação vegetativa de Eucalyptus: princípios básicos e a sua evolução no Brasil. Piracicaba: IPEF, 2000. 11 p. (Circular Técnica, 192).

HYAMS, D. CurveExpert 1.3: A comprehensive curve fitting system for Windows. Shareware, Starkville, Mississippi, 1997.

PAIVA, H. N.; GOMES, J. M. Propagação vegetativa de espécies florestais. Viçosa: UFV, 2005. 46 p. (Caderno Didático, 83).

TITON, M. et al. Eficiência das minicepas e microcepas na produção de propágulos de clones de Eucalyptus grandis. Revista Árvore, Viçosa, v. 27, n. 5, p. 619-625, set./out. 2003.

WENDLING, I. Rejuvenescimento de clones de Eucalyptus grandis por miniestaquia seriada e micropropagação. 2002. 98 f. Tese (Doutorado em Ciência Florestal)-Universidade Federal de Viçosa, Viçosa, 2002.

WENDLING, I. et al. Efeito do regulador de crescimento AIB na propagação de clones de Eucalyptus spp. por miniestaquia. Revista Árvore, Viçosa, v. 24, n. 2, p. 187-192, abr./jun. 2000a.

WENDLING, I. et al. Propagação clonal de híbridos de Eucalyptus spp. por miniestaquia. Revista Árvore, Viçosa, v. 24, n. 2, p. 181-186, abr./jun. 2000b.

XAVIER, A.; WENDLING, I. Miniestaquia na clonagem de Eucalyptus. Viçosa: SIF, 1998. 10 p. (Informativo Técnico SIF, 11).

XAVIER, A.; WENDLING, I.; SILVA, R. L. Silvicultura clonal: princípios e técnicas. Viçosa: UFV, 2009. $272 \mathrm{p}$. 